\title{
Mapeamento de processos: um estudo de caso na central de aquisições de uma instituição federal de ensino superior
}

O objetivo deste trabalho foi identificar, descrever e mapear o processo de compras e contratações realizados por meio da Central de Aquisições da Universidade Federal de Santa Maria (UFSM). Para a realização deste, primeiramente, fez-se uma pesquisa sobre as metodologias utilizadas no mapeamento de processos, definindo-se assim a mais adequada e adaptando-a para a realidade do objeto de estudo. Os dados foram obtidos por meio de entrevistas com os servidores responsáveis pela execução do processo a fim de obter uma descrição detalhada das tarefas desempenhadas durante o mesmo. Estes dados foram transcritos para uma tabela, onde foi possível identificar todos os participantes ativos no processo, além das atribuições de cada um. Para o mapeamento dos processos, utilizou-se o Bizagi Modeler, uma ferramenta freeware de gestão de processos que permite a criação de diversos tipos de diagramas. 0 resultado gerou grande contribuição no setor, na forma da documentação e registro dos processos, além da metodologia simplificada, que pode ser utilizada em futuros mapeamentos.

Palavras-chave: Processos; Gestão de processos; Mapeamento processos.

\section{Process Mapping: A Case Study at the Procurement Center of a Federal Higher Education Institution}

\begin{abstract}
The objective of this work was to identify, describe and map the procurement and hiring process carried out through the Central Purchasing Center of the Federal University of Santa Maria (UFSM). To accomplish this, firstly, a research was done on the methodologies used in the process mapping, thus defining the most appropriate and adapting it to the reality of the object of study. Data were obtained through interviews with the servers responsible for executing the process in order to obtain a detailed description of the tasks performed during the process. These data were transcribed to a table, where it was possible to identify all the active participants in the process, as well as their assignments. For process mapping, we used Bizagi Modeler, a freeware process management tool that allows the creation of various types of diagrams. The result generated a great contribution in the sector, in the form of documentation and registration of processes, as well as the simplified methodology that can be used in future mappings.
\end{abstract}

Keywords: Processes; Processes management; Mapping processes.

Topic: Gestão Pública

Reviewed anonymously in the process of blind peer.
Received: 05/01/2019

Approved: 05/03/2019
André de Toledo Paines

Universidade Federal de Santa Maria, Brasil

http://lattes.cnpq.br/2279311028611096

andrepaines@gmail.com

Ana Paula da Costa Mayer

Universidade Federal de Santa Maria, Brasil

http://lattes.cnpq.br/3715133324279831

paulamayer@ufsm.br

Gabriella Lisbôa Helbert

Universidade Federal de Santa Maria, Brasil

http://lattes.cnpq.br/9929752185515969

gabriellahelbert@gmail.com
Jéssica Schmidt

Universidade Federal de Santa Maria, Brasil http://lattes.cnpq.br/9436839404698292

jessica.poa1@hotmail.com

Mariane Rodrigues Volz de Aguiar

Instituto Federal Farroupilha, Brasi

http://lattes.cnpq.br/9286046222433951

marianeaguiarmra@gmail.com

Daniel Arruda Coronel

Universidade Federal de Santa Maria, Brasil

http://lattes.cnpq.br/9265604274170933

http://orcid.org/0000-0003-0264-6502

daniel.coronel@uol.com.br
Referencing this:

PAINES, A. T.; MAYER, A. P. C.; HELBERT, G. L.; SCHMIDT, J.; AGUIAR, M. R. V.; CORONEL, D. A.. Mapeamento de processos: um estudo de caso na central de aquisições de uma instituição federal de ensino superior. Revista Brasileira de Administração Científica, v.10, n.1, p.43-56, 2019. DOI: http://doi.org/10.6008/CBPC2179684X.2019.001.0004 


\section{INTRODUÇÃO}

Atualmente, as organizações vivem um cenário de crescente competitividade e, para atender a esta realidade, elas vêm buscando soluções para melhor estruturar e integrar seus processos, criando maior flexibilidade e agilidade em suas operações. Da mesma forma, na Administração Pública, os novos sistemas e a demanda da sociedade por maior transparência e qualidade na prestação de seus serviços geram uma crescente preocupação com a otimização dos seus processos (CATELLI et al., 2004)

Para Martin (2001), as organizações tradicionais começaram a perceber que o seu principal problema consistia no fato de que as suas estruturas gerenciais e os processos de trabalho estavam se tornando defasados, pois foram desenhados antes da tecnologia moderna. Para Villela (2000), "esta mudança tecnológica e a sua inserção em um ambiente de competição globalizada tornam necessário o redesenho das funções organizacionais exercidas pela maioria das pessoas, de modo a adequá-las à realidade do mercado", com objetivo de aumentar a competitividade e o valor organizacional de acordo com os preceitos da era moderna.

De acordo com Baldam et al. (2007), a crescente busca de aperfeiçoamentos na qualidade dos produtos, durante as décadas de 1970 e 1980, deu origem ao primeiro grande movimento de análise intensiva dos processos dentro de programas de racionalização do trabalho. $\mathrm{O}$ foco desses programas era a eliminação de defeitos, por melhoria contínua, de modo que os produtos terminassem com nenhum defeito.

Segundo Oliver (2010), todo planejamento estratégico de uma organização é composto por uma série de processos, e muitas organizações desperdiçam tempo em detalhes que nem sempre são necessários para sua realização. Este erro é decorrente da falta de conhecimento por parte das empresas sobre a melhor maneira de execução dos seus processos e das condições básicas para que ocorram. Desta forma, o conhecimento dos processos representa uma vantagem competitiva para a organização, pois auxilia na análise crítica e na tomada das ações necessárias em todos os seus níveis.

Para Araújo et al. (2009), o objetivo da nova gestão pública consiste em substituir a gestão pública tradicional por processos e técnicas de gestão do tipo empresarial. Além disso, Araújo et al. (2009) afirma que as preocupações com os problemas de gestão deixam de ser a principal e única preocupação, passando a atenção a centrar-se num fenômeno mais complexo, que é a governança. Neste sentido, com a proposta de realizar um mapeamento de processos na organização escolhida, o objetivo principal do trabalho é identificar, mapear e descrever o processo de aquisições e contratações de bens e serviços, realizadas por meio de uma Central de Aquisições. Mais especificamente, o trabalho objetiva identificar os participantes ativos no processo e suas atribuições.

Ressalta-se que o estudo é importante para a instituição em questão, pois não existe uma metodologia específica que defina o funcionamento dos seus processos. Assim, este trabalho pode contribuir para a definição de uma metodologia simplificada para análise de processos, adaptada para a realidade dos setores envolvidos, bem como formar uma base teórica consistente, que possa ser utilizada em estudos 
futuros. Como existem diversos processos e um estudo completo deles exigiria um período maior, delimitouse, para este estudo, o mapeamento apenas às aquisições e contratações realizadas através da Central de Aquisições.

O artigo está estruturado em outras quatro seções, além desta introdução. Na segunda seção, apresenta-se a fundamentação teórica; na seção seguinte, abordam-se os procedimentos metodológicos utilizados; na seção quatro, os resultados são analisados e discutidos, e, por fim, são apresentadas as principais conclusões.

\section{REVISÃO TEÓRICA}

\section{Gerenciamento e mapeamento de processos}

No entendimento de Tavares (2011), os processos são um conjunto de atividades e etapas interligadas que agregam valor a insumos (inputs) gerando produtos (outputs) específicos. Já para Johansson et al. (1995), estes outputs devem adicionar valor e criar um resultado que seja mais útil e eficaz ao recebedor acima ou abaixo da cadeia produtiva. Já Chang (2006), dentro de uma perspectiva de negócios, caracteriza o processo como um fluxo de atividades coordenadas e padronizadas, executadas por pessoas ou máquinas, que pode atravessar fronteiras funcionais ou departamentais, com o intuito de atingir um objetivo de negócio que crie valor para os clientes internos ou externos.

Para Gonçalves (2000), um processo pode ser qualquer atividade que recebe uma entrada, agrega valor e gera uma saída, seja para um cliente interno ou para um cliente externo. Desta forma, os processos utilizam os recursos da organização para oferecer resultados objetivos aos clientes. Gonçalves (2000) ainda salienta que, algumas vezes, as atividades essenciais (aquelas atividades que são críticas para que sejam atingidos os objetivos da empresa) são chamadas de processos, pois envolvem um conjunto de atividades operacionais e diversos níveis organizacionais e práticas gerenciais.

No entendimento de Smith et al. (2007), o processo de negócio é um conjunto complexo de atividades transacionais colaborativas e dinamicamente coordenadas, que entregam valor para os clientes. Os autores caracterizam tais processos como complexos, longos, dinâmicos, automatizáveis, dependentes da tecnologia e de julgamento e apoio da inteligência humana, dentre outras características.

De acordo com Chiavenato (2010), os processos são meios pelos quais é possível alcançar fins (resultados), e um processo é qualquer atividade que utiliza recursos para transformar insumos em produtos. Já Cruz (2005) explica que, quando um processo é muito complexo, recomenda-se que ele seja dividido em subprocessos. Dessa forma, a concentração em cada segmento do processo se dá de forma mais detalhada e demonstra os componentes pertencentes a qualquer processo de negócio. Seguindo do mais abrangente para o mais detalhista, têm-se os seguintes componentes, conforme o quadro 1.

Segundo Quinn (1992), a importância dos processos de trabalho aumenta à medida que as empresas ficam com conteúdo cada vez mais intelectual ou nas empresas de conteúdo puramente intelectual, 
afastando-se do modelo fabril. Gonçalves (2000) aborda ainda que os processos não criam apenas as eficiências de hoje, mas também garantem o futuro por meio de habilidades que se aplicam aos novos produtos. No entendimento de Quinn (1992), a rápida inovação dos processos resulta em capacitações organizacionais melhoradas que permitem, por exemplo, que os novos produtos sejam desenvolvidos mais rapidamente.

Quadro 1: Componentes de um Processo de Negócio.

\begin{tabular}{|l|l|}
\hline COMPONENTE & DESCRIÇÃo \\
\hline Subprocesso & $\begin{array}{l}\text { É o primeiro nível abaixo do processo propriamente dito. É mais detalhado que o processo, porém } \\
\text { ainda é relativamente abrangente. }\end{array}$ \\
\hline Atividade & $\begin{array}{l}\text { As atividades são oriundas do detalhamento dos subprocessos. Este nível apresenta uma relativa } \\
\text { ponderação entre abrangência e detalhamento, não tendendo a extremos. }\end{array}$ \\
\hline Procedimento & Oriundo do detalhamento de uma atividade. Apresenta um nível maior de detalhamento. \\
\hline Tarefa & $\begin{array}{l}\text { É o último nível de detalhamento. São oriundas do detalhamento de um procedimento. Este nível } \\
\text { tende ao máximo de detalhe. }\end{array}$ \\
\hline
\end{tabular}

Fonte: Cruz (2005).

Atualmente, uma gestão de processos eficaz é bastante importante para qualquer organização, pois permite que sua estrutura e seus processos gerenciais sejam modernizados, oferecendo-lhe oportunidade de agregação de valor e melhoria no atendimento das suas necessidades e dos seus clientes. De acordo com Araújo (2012), a Gerência de Processos (GP) consiste no planejamento, na organização, na direção e no controle dos processos existentes dentro de uma organização, e se caracteriza como uma gestão mais específica que busca entender aos seus processos, na intenção de melhorar o seu desempenho e seus resultados.

Segundo Gonçalves (2000), gerenciar as empresas pelo ponto de vista dos processos é um dos grandes desafios da gestão eficaz de recursos humanos nas empresas, nas próximas décadas. A adoção pelas empresas de uma administração baseada em processos desenvolve e salienta a importância dos papéis ligados a processos, que incluem a liderança do grupo, a ligação entre as pessoas, a facilitação dos mecanismos grupais, o desenvolvimento de conhecimento, o gerenciamento das agendas de compromissos e o suporte ao funcionamento das equipes.

Segundo Madiolo et al. (2006), o funcionamento adequado de uma organização implica a existência de um modelo de gestão definido. Em uma organização orientada por processos, as pessoas passam a trabalhar no processo e não mais nas áreas da empresa. Madiolo et al. (2006) explica que estas áreas perdem muito de sua importância ou simplesmente deixam de existir, e complementam, dizendo que a GP difere da gestão por funções tradicionais por pelo menos três motivos: empregam objetivos visando ao cliente, os empregados e os recursos são agrupados para produzir um trabalho completo.

Para Melo (2000), a GP vai desde o nível decisório mais alto da empresa até o nível executivo mais simples e, embora seja complexa na sua concepção e execução, uma vez que envolve aspectos delicados e susceptibilidades nos diversos níveis hierárquicos, atravessa invariavelmente algumas etapas, conforme apresentado no quadro 2 . 
Quadro 2: Etapas da Gerência de Processos.

\begin{tabular}{|l|l|}
\hline \multicolumn{1}{|c|}{ ETAPA } & \multicolumn{1}{c|}{ CARACTERÍSTICAS } \\
\hline $\begin{array}{l}\text { Identificação e análise dos } \\
\text { processos de organização }\end{array}$ & Saber o funcionamento geral de qualquer empresa é essencial para total domínio da situação. \\
\hline $\begin{array}{l}\text { Estabelecimento de metas } \\
\text { de melhoria e } \\
\text { aperfeiçoamento desses } \\
\text { processos }\end{array}$ & $\begin{array}{l}\text { É essencial que sejam estabelecidas metas, para que se tenha uma visão real dos resultados } \\
\text { alcançados. Cada meta alcançada é uma satisfação para a equipe de trabalho, assim como se } \\
\text { torna o início para mais um passo. A partir desse momento, chegamos à melhoria contínua. }\end{array}$ \\
\hline $\begin{array}{l}\text { Avaliação dos processos } \\
\text { pelos resultados frente ao } \\
\text { cliente }\end{array}$ & $\begin{array}{l}\text { Se o alvo é o cliente, então será por seu intermédio que se avaliará o acerto. Não adianta tornar } \\
\text { o trabalho fácil para os servidores, se seu objetivo principal, o cidadão que está no papel de } \\
\text { cliente, não está agradando. A função de quem está gerenciando é encontrar esse ponto de } \\
\text { interseção entre técnicas de trabalho de equipe e satisfação do cliente, que é justamente a } \\
\text { busca de resultados, por meio de pesquisas, opiniões etc. }\end{array}$ \\
\hline $\begin{array}{l}\text { Normalização dos estágios } \\
\text { de desenvolvimento } \\
\text { atingidos pelos processos }\end{array}$ & $\begin{array}{l}\text { Saber o ponto de equilíbrio de cada processo é uma das características para quem está } \\
\text { gerenciando. }\end{array}$ \\
\hline
\end{tabular}

Fonte: Melo (2000).

Dinsmore et al. (2014) caracteriza a GP como uma forma de organização e estruturação das entidades para realocação dos recursos disponíveis como pessoas, capital, bens, entre outros, nas áreas deficientes, para que assim ocorra uma melhoria da organização como um todo. Lima (2007) complementa, afirmando que esse gerenciamento necessita participação de todas as pessoas inseridas nas atividades da organização, sendo que a base dessa gestão é a informação gerada por essas atividades.

Já para Damelio (2011), a análise estruturada dos processos permite reduzir custos no desenvolvimento de produtos e serviços e de falhas de integração entre sistemas, além de possibilitar um melhor entendimento dos processos atuais e a eliminação ou simplificação dos processos que necessitam de mudanças. Fadul et al. (2008) destaca que a administração de processos é fundamental para qualquer organização, seja ela pública ou privada, pois resulta na eficiência dos processos, por meio da organização/reorganização e formalização destes.

Para Batista (1996), para existir o efetivo gerenciamento de processos no setor público, é importante que os conceitos e princípios fundamentais dessa maneira de gerenciar sejam do conhecimento de todos na organização. As principais definições que podem auxiliar os administradores públicos no gerenciamento de processos são qualidade, relação custo/benefício, processo, insumos e fornecedores, clientes e produtos e serviços, características do produto/serviço, verificação de qualidade e medidas não financeiras. Assim, percebe-se a importância de uma gerência de processos executada de forma eficaz em uma organização, inclusive aquelas do setor público. O gerenciamento das organizações sob este ponto de vista pode ser feito de diversas formas, e uma destas pode ser a utilização da ferramenta de Mapeamento de Processos.

Segundo Hunt (1996), o Mapeamento de Processos é uma ferramenta gerencial analítica e de comunicação que tem a intenção de ajudar a melhorar os processos existentes ou de implantar uma nova estrutura voltada para processos. Este tipo de mapeamento é uma excelente ferramenta para o melhor entendimento dos processos atuais, eliminação ou simplificação dos que necessitam de mudanças e a melhoria dos serviços, pois permite que as pessoas envolvidas reflitam de maneira sistemática e estruturada sobre as práticas do dia a dia. 
De acordo com Campos (2009), o mapeamento de processos é a "modelagem do processo com representação gráfica mostrando todas as fases e o fluxo do processo, em níveis de detalhes diferenciados, caracterizando atividades de trabalho, tarefas, operações, responsabilidades etc.". Para Rother et al. (2000), o mapeamento de processos é uma ferramenta que pode fornecer uma figura do processo de produção como um todo, incluindo as atividades agregadoras e não agregadoras de valor.

Biazzo (2000) complementa este raciocínio, explicando que mapear processos significa construir um mapa com o objetivo de realçar graficamente a relação entre as atividades, pessoal, informações e objetos envolvidos e sua abordagem é baseada em uma estratégia precisa para reconstrução das ações organizacionais e em um foco específico para análise. Segundo Biazzo (2000), o mapeamento dos processos é composto pelas seguintes etapas, detalhadas no quadro 3.

Quadro 3: Etapas do Mapeamento de Processos.

\section{ETAPAS DO MAPEAMENTO DE PROCESSOS}

Definição das fronteiras e dos clientes do processo, dos principais inputs e outputs e dos atores envolvidos no fluxo de trabalho. Entrevistas com os responsáveis pelas várias atividades dentro do processo e estudo dos documentos disponíveis.

Criação de um modelo com base na informação adquirida e revisão passo a passo do modelo seguindo a lógica do ciclo de "author-reader".

Fonte: Biazzo (2000)

Albuquerque et al. (2007) explica que, após realizado o mapeamento, este gera um mapa que dispõe as diversas interações da estrutura da organização, englobando as atividades da totalidade da organização ou podendo evidenciar apenas um processo. Pode-se concluir, portanto, que, segundo Albuquerque et al. (2007), a visualização de cada um dos processos demonstra suas especificidades, assim como cada etapa e atividade que os compõem, facilitando, dessa forma, a identificação de possíveis problemas que impedem o desenvolvimento dos processos e, consequentemente, da organização.

Adair et al. (1996) observa que o mapeamento dos processos evita os detalhes e concentra-se na apresentação de uma descrição gráfica e compreensível. Adair et al. (1996) explica que o resultado do mapeamento é um diagrama que mostra como se articulam as principais etapas de um processo, fornecendo uma base para a fase do redesenho e para a visualização das mudanças. Já para Harrington (1993), o resultado do mapeamento consiste em um fluxograma que descreve graficamente um processo existente, ou um novo proposto, usando símbolos simples, linhas e palavras, de forma a apresentar graficamente as atividades e a sequência que o compõem.

De acordo com Mello (2011), escolher o mapeamento como ferramenta de melhoria, quando empregado de forma correta, permite documentar todos os elementos que compõem um processo e corrigir qualquer um desses elementos que esteja com problemas, sendo uma ferramenta que auxilia na deteç̧ão das atividades não agregadoras de valor. Para Maranhão et al., (2004), o mapeamento realizado nos processos é mais bem compreendido pelos funcionários da organização por meio da exposição dos mapas (fluxos) em documentos gerados, sejam em meios físicos, seja em relatórios ou manuais ou em mídias virtuais, como em softwares. 
Campos et al. (2012) ressalta que o mapeamento auxilia a organização a enxergar claramente os seus pontos fortes e fracos, bem como aqueles que precisam ser melhorados, como gargalos, tarefas de baixo valor agregado, retrabalhos e excesso de documentação, "além de ser uma excelente forma de melhorar o entendimento sobre os processos e aumentar o desempenho das atividades" (CAMPOS et al., 2012).

Leal (2003) ressalta a eficiência do mapeamento dos processos, pois a partir deste, é possível identificar a origem dos desperdícios dentro da organização, o que ajuda a evitar a utilização de procedimentos isolados que não fazem parte do processo como um todo. Cruz (2010) complementa, afirmando que, após a identificação dos desperdícios pelo mapeamento, as técnicas de reengenharia e redesenho dos processos podem resolvê-los. Observa-se, enfim, a importância e a utilidade de um mapeamento de processos eficaz dentro das organizações. Conforme exposto, esta ferramenta permite verificar e corrigir as fraquezas existentes no processo e, em adicional, proporcionar melhorias na sua execução.

Torres (2012) observa que a grande maioria de analistas e operadores considera a Lei 8.666/93, que regulamenta as compras no setor público, "muito detalhista, burocrática e rígida, que só traz morosidade, corrupção e ineficiência na operação e funcionamento da administração pública brasileira" (TORRES, 2012). Desta forma, uma gerência de processos eficaz pode tornar possível verificar, além das eventuais falhas, a quantidade de recursos envolvidos na execução de diversos processos.

\section{O Processo de compras em Organizações Governamentais}

De acordo com Serviço Federal de Processamento de Dados (SERPRO), no MPOG (2011), orientar-se por processos permite que as organizações públicas atuem com foco no cidadão. Para alcançar este objetivo, é necessário modelar, aprimorar e gerenciar seus processos, a fim de definir os resultados esperados deste gerenciamento, podendo assim garantir maior controle e qualidade nos serviços prestados. Segundo Leenders et al. (1997), com os avanços tecnológicos, houve grandes transformações na gestão dos recursos logísticos das organizações, em especial na atividade de compras. Esta atividade deixou de ser operacional, assumindo um papel mais estratégico, com grande enfoque na eficiência e eficácia do processo.

Silva et al. (2012) observa que, no Brasil, as compras governamentais movimentam recursos estimados entre 10 e $15 \%$ do PIB. A fim de abarcar essa considerável fatia do mercado, importantes setores da economia buscam se ajustar às demandas previstas nos editais de licitação. Teixeira et al. (2015) considera que a centralização de compras proporciona benefícios concretos, tais como sinergia, compartilhamento de recursos e know-how, coordenação de estratégias e o poder de negociações em pool. Teixeira et al. (2015) classifica em três categorias principais os benefícios das compras centralizadas: economias de escala; economias de informação e aprendizado; e economias de processo.

Já no entendimento de Fenili (2016), a adoção do paradigma das compras compartilhadas posiciona a Administração Pública como ator de destaque junto ao mercado, ao passo que as compras compartilhadas podem trazer benefícios, tais como a economia de escala e a racionalização processual. No entanto, Fenili 
(2016) observa que deve se ter uma visão acurada desta prática. Ainda segundo Fenili (2016), uma característica principal de uma central de compras é a capacidade de inteligência no que concerne ao planejamento e à organização das demandas, bem como ao relacionamento com os clientes internos.

Assim como a grande maioria das organizações públicas, as IFES apresentam diversas dificuldades no processo de compras devido à sua alta regulamentação e burocracia. Outro grave problema da Administração Pública, destacado por Villela (2000) para ressaltar a importância do mapeamento dos processos, é o fato de que muitos servidores se aposentam ou migram para outros serviços, e a organização não pode arriscar a perder lições e experiências conseguidas ao longo de muitos anos. Neste sentido, o mapeamento, com sua função de registro e documentação histórica, pode fornecer subsídios aos novos servidores da instituição para a correta execução dos processos.

\section{MATERIAIS E MÉTODOS}

\section{Delineamento do Estudo}

Sendo o objeto a ser estudado o processo de compras e contratações realizado a partir da Central de Aquisições da UFSM, optou-se como tipo de delineamento o estudo de caso, que é considerado por Yin (2010) como uma forma de se fazer pesquisa investigativa de fenômenos atuais dentro de seu contexto real, em situações em que as fronteiras entre o fenômeno e o contexto não estão claramente estabelecidas. Segundo Gil (2008), nos estudos de caso os dados podem ser obtidos mediante análise de documentos e artefatos físicos, entrevistas, depoimentos pessoais e observação. Para a realização deste estudo, foram utilizadas as técnicas de coleta de dados, observação, entrevistas e pesquisa documental.

Para o presente estudo de caso, foi definida a metodologia qualitativa, com realização de pesquisa descritiva. Assim, considerando a forma de abordagem do problema, este trabalho tem características essencialmente qualitativas, em virtude de este tipo de estudo privilegiar o significado das informações coletadas (BOAVENTURA, 2004). Para Vergara (2011), "a pesquisa descritiva expõe as características de determinada população ou de determinado fenômeno. Pode também estabelecer correlações entre variáveis e definir sua natureza". Já para Gil (2008), a pesquisa descritiva é uma pesquisa que tem como objetivo primordial a descrição das características de determinada população ou fenômeno, ou então, o estabelecimento das relações entre as variáveis.

\section{Técnica de Coleta de Dados}

O levantamento de dados ocorreu por meio de observação do ambiente de trabalho, análises documentais, revisão bibliográfica, subsidiada por artigos, livros, ensaios acadêmicos etc. que tratam da temática proposta pelo estudo. Tendo em vista que o presente estudo se limitou a mapear somente o funcionamento da Central de Aquisições do Departamento de Material e Patrimônio (DEMAPA), foram realizadas entrevistas informais com os servidores lotados no departamento que desempenham as 
atividades inerentes a este processo, envolvendo perguntas relacionadas ao seu funcionamento e também um pedido para que estes servidores descrevessem as atividades desempenhadas, totalizando quatro sujeitos entrevistados.

Já a análise documental se deu em arquivos particulares da organização, e a observação do ambiente ocorreu durante a jornada de trabalho no departamento. Logo após, foi feita comparação dos dados obtidos com o referencial teórico pesquisado no trabalho e, partindo dos resultados obtidos, foram levantadas possibilidades de melhorias nos processos executados pelo departamento e propostas sugestões para o aumento da sua efetividade.

\section{Técnica de Análise dos Dados}

Os dados obtidos durante a pesquisa foram organizados em tabelas que descreveram detalhadamente o funcionamento de cada processo e suas respectivas etapas. Esta descrição permitiu que fosse mapeada a quantidade de participantes ativos e a função que cada um desempenha na execução dos processos. Após a descrição, o mapeamento do processo se realizou por meio do uso do Bizagi Modeler, uma ferramenta freeware de gestão de processos que permite a criação de diversos tipos de diagramas. 0 mapeamento no Bizagi ofereceu um fluxograma que descreve o processo escolhido, permitindo identificar graficamente os subprocessos existentes e as tarefas realizadas por cada participante envolvido neles, facilitando a compreensão do processo como um todo.

\section{Limitações do Método de Estudo}

Gareth (2006) considera que a padronização causada pelo controle é a grande desvantagem da técnica de mapeamento de processos. Segundo Gareth (2006), esta padronização torna o trabalho extremamente rotineiro no núcleo operacional, por ser simples e repetitivo, não exigindo incentivos para desenvolver as capacidades dos funcionários (colaboradores) e habilidades, fazendo com que muitos se tornem insatisfeitos com a organização, o que pode acarretar várias formas de resistências dos trabalhadores como absenteísmo, altas taxas de rotatividade, greves, apatia, descuido e falta de comprometimento com a organização.

Gareth (2006) ainda destaca que este método de padronização é adequado para a produção, mas não para as pessoas, e que a flexibilidade e a divisão de tarefas e responsabilidades têm ênfase nas empresas orgânicas (que acompanham as mudanças do mercado, inovando e se reinventando), que acabam não se encaixando tão bem nos princípios da padronização (que buscam um mercado constante).

\section{RESULTADOS E DISCUSSÃO}

A Central de Aquisições é uma subunidade administrativa vinculada ao DEMAPA da Universidade Federal de Santa Maria (UFSM). Através da Central de Aquisições são centralizadas as solicitações de compras e de serviços comuns a todas as subunidades da UFSM, conforme o planejamento anual de licitações e 
legislação vigente. De acordo com informações da Pró-Reitoria de Administração, as atividades da Central de Aquisições tiveram início no ano de 2010, e sua finalidade inicial era centralizar os processos de compras e de contratações de serviços por meio do seu planejamento.

Desta forma, os processos de aquisições de bens ou serviços, que passam pela Central de Aquisições, objetivam atingir as seguintes metas: padronização dos produtos; economicidade e eficiência no gasto público; diminuição no tempo de elaboração dos Termos de Referência e nas descrições completas de produtos e serviços, incluindo a tramitação, aprovação e liberação dos extratos de Registros de Preços, melhorando as condições de atendimento e consulta aos usuários do Sistema de Informações para o Ensino (SIE) e compradores das unidades e subunidades.

Destaca-se que, entre as atribuições da Central de Aquisições, estão a elaboração e o gerenciamento de processos administrativos contra empresas inadimplentes; negociações com fornecedores; realização de solicitações de compras de itens comuns a todas as unidades da universidade; liberação e controle de registros de preços; montagem de processos de compra compartilhada e atendimento às solicitações de adesão à ata de registro de preços por outras Unidades Gestoras do orçamento da União. Porém, para este estudo de caso, optou-se por mapear somente o processo de compras e contratações de bens ou serviços pela unidade.

Desta forma, com a Central de Aquisições, as despesas da UFSM passaram a obedecer a uma nova sistemática, que perpassa as fases do planejamento de despesas comuns, evitando o fracionamento da despesa pública, até a fase de negociação de entrega e instauração de processos administrativos contra empresas inadimplentes. Portanto, com a implantação da Central de Aquisições, o sistema SIE passou a disponibilizar uma unidade administrativa onde as Unidades Gestoras Responsáveis (UGR) passaram a ter a opção de solicitar empenhos para compras e contratações de bens e serviços comuns, conforme sua disponibilidade de recursos orçamentários. A partir da coleta e análise dos dados, descreveram-se detalhadamente as atividades desempenhadas neste processo, conforme demonstra o quadro 4.

Quadro 4: Descrição das Atividades e Tarefas do Processo de Solicitação de Compra da Central de Aquisições.

Nome do Processo: Compras e Contratações de Bens ou Serviços pela Central de Aquisições

Início do Processo: A unidade administrativa Central de Aquisições realiza o planejamento da relação de produtos e serviços que serão licitados de acordo com:

Análise dos itens a serem licitados e pesquisa de mercado (durabilidade, economicidade, sustentabilidade dos produtos etc.); Descrição completa de produtos e serviços, com o auxílio de profissionais da área técnica das unidades solicitantes ou comissões específicas, conforme especificidades dos produtos ou serviços;

Definição de quantitativos totais por itens;

Pesquisa de preços praticados no mercado, com elaboração de estimativa do valor máximo para contratação; Justificativa de necessidade de contratação.

Fim do Processo: Acompanhamento mensal dos prazos de vigência dos Registros de Preços e reinício do processo.

Descrição das atividades e tarefas do Processo

A Central de Aquisições elabora Solicitação de Compras no SIE (aplicação código 5.5.66) e tramita para análise da Direção do DEMAPA, sem reserva de recursos orçamentários;

2 A Direção do DEMAPA analisa o processo e encaminha para correções pela Central de Aquisições ou tramita diretament

2 para elaboração do edital, minuta de contrato e anexos, pela Coordenação de Materiais, Editais e Contratos (DIMECI);

3 A DIMECl aprova a solicitação de licitação no SIE e encaminha documentação impressa para abertura de processo;

4 O Departamento de Arquivo Geral - DAG abre o processo e o retorna para a DIMECl;

5 A DIMECl efetua a montagem e instrução processual; 


\begin{tabular}{|c|l|}
\hline 6 & $\begin{array}{l}\text { A DIMECI encaminha o Processo de Licitação para análise do Ordenador de Despesas (Pró-Reitoria de Administração - } \\
\text { PRA); }\end{array}$ \\
\hline 7 & $\begin{array}{l}\text { O Ordenador de Despesas realiza um dos seguintes procedimentos: aprova ou solicita correções, retornando o processo } \\
\text { para a DIMECl; }\end{array}$ \\
\hline 8 & $\begin{array}{l}\text { Conforme o caso, a DIMECI procede às correções recomendadas e após encaminha para análise e parecer da Procuradoria } \\
\text { Jurídica da UFSM (PROJUR); }\end{array}$ \\
\hline 9 & $\begin{array}{l}\text { A PROJUR realiza um dos seguintes procedimentos: aprova e retorna à DIMECI para agendamento da data de abertura da } \\
\text { sessão pública do pregão eletrônico; ou retorna à DIMECI para correções; }\end{array}$ \\
\hline 10 & A Coordenação de Licitações realiza a fase externa do processo licitatório; \\
\hline 11 & $\begin{array}{l}\text { A Coordenação de Licitações faz a divulgação e publicidade do edital no sistema SIASGNET, onde será gerada a publicação } \\
\text { do extrato do edital de licitação no Diário Oficial da União (DOU); }\end{array}$ \\
\hline 12 & $\begin{array}{l}\text { Encerrada a fase externa do processo licitatório, o Registro de Preços é encaminhado para a Central de Aquisições para } \\
\text { disponibilização às UGRs; }\end{array}$ \\
\hline 13 & $\begin{array}{l}\text { As UGRs solicitam os empenhos SIE (aplicação código 2.3.1) conforme disponibilidade orçamentária e de quantitativos } \\
\text { disponíveis para os itens registrados através da Central de Aquisições (aplicação código 5.5.99.03.28); }\end{array}$ \\
\hline 14 & \begin{tabular}{l} 
Acompanhamento mensal dos prazos de vigência dos Registros de Preços, e reinício do processo. \\
\hline
\end{tabular}
\end{tabular}

Por meio da descrição das atividades do processo, pode-se mapear o processo de Compras e Contratações de Bens ou Serviços pela Central de Aquisições e obter o fluxograma deste mapeamento. Neste fluxograma, os participantes do processo são dispostos de cima para baixo, e as atividades relativas a eles são colocadas linearmente, obedecendo à ordem de ocorrência. O fluxograma do processo de Compras e Contratações de Bens ou Serviços pela Central de Aquisições é apresentado na figura 1.

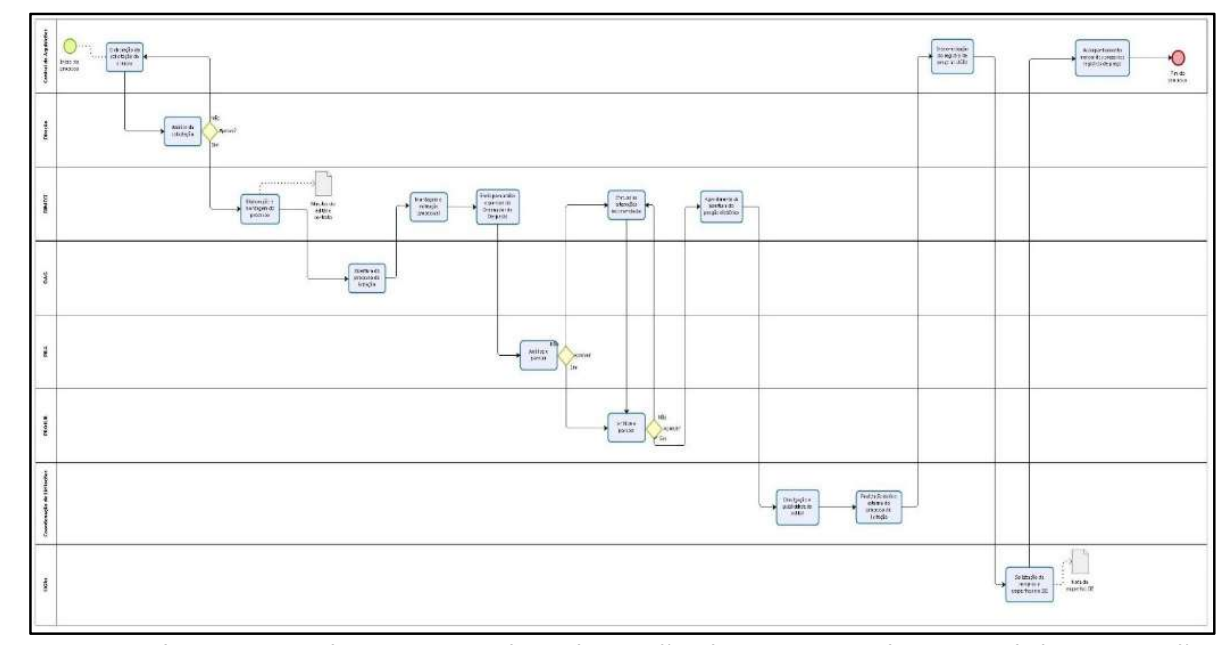

Figura 1: Fluxograma do Processo de Solicitação de Compras da Central de Aquisições.

Observa-se, por meio da descrição das atividades e da análise do fluxograma, a participação de oito agentes no processo, executando catorze atividades dentro deste, podendo ser até dezoito, uma vez que algumas podem ser repetidas, caso haja erros na sua execução. As solicitações de compras serão emitidas pelas UGRs e podem ser feitas a qualquer momento, desde que o registro de preço esteja ativo. Para cada solicitação de compra é feito um acompanhamento do prazo de entrega, de modo que estas duas atividades se repetem diversas vezes durante a validade do registro de preço.

\section{CONSIDERAÇÕES FINAIS}

O presente trabalho teve como proposta mapear o Processo de Solicitação de Compra na Central de Aquisições do DEMAPA. Ao longo do estudo, foi possível perceber que a ferramenta de mapeamento de 
processos possibilita um melhor entendimento quanto ao funcionamento de cada setor da instituição, ratificando as opiniões de diversos autores, contidas no referencial teórico.

O objetivo principal do trabalho foi atingido na medida em que foram expostas as fases que envolvem as etapas que iniciam no planejamento e terminam nas aquisições de bens e serviços a partir do trabalho de uma Central de Compras e Contratações, permitindo identificar e mapear os processos de planejamento, instrução do processo licitatório, e disponibilização dos registros de preços de preços pela Central de Aquisições.

Destaca-se que a UFSM é uma das poucas instituições federais que instituíram, na sua estrutura física, uma unidade administrativa com a finalidade de centralizar compras e contratações de bens e serviços comuns. Além disso, a instituição adequou seu sistema de controle, utilizando-se de uma ferramenta interna para facilitar o processo da despesa, aliando a técnica de planejamento com a sustentabilidade de compras. Desta forma, com o trabalho da Central de Aquisições, alguns itens possuem um processo de contratação ou aquisição mais ágil, devido ao planejamento de unidade específica para compras e à rotatividade do sistema de registro de preços.

Assim, através de entrevistas informais e observação documental, foi possível visualizar o processo como um todo e entender como funcionam as fases que antecedem o processo licitatório e que terminam no processo de aquisição de bens ou contratação de serviços pelas unidades e subunidades da UFSM, por meio da Central de Aquisições.

Ao cumprir o objetivo específico de identificar os participantes ativos de cada processo, foi possível perceber quais participantes possuem maior demanda de trabalho. Além disso, segundo os entrevistados, e considerando o que se pôde perceber durante o estudo, o principal ponto crítico é em relação à celeridade processual, sendo que os problemas mais citados foram as cobranças administrativas, mas não fizeram parte desta abordagem por não serem objeto deste estudo.

O principal fator de limitação deste trabalho está relacionado ao fato de haver diversos outros processos desempenhados pelo departamento, o que possibilitou o mapeamento de apenas um deles. Neste sentido, o estudo deixa como sugestões para trabalhos futuros mapear os demais processos desempenhados pelo departamento, classificando-os em processo, subprocesso, atividades e tarefas. Outro ponto a ser abordado é que o processo escolhido foi mapeado linearmente, sem considerar eventuais erros que possam ocorrer na sua execução e que provoquem uma tramitação mais demorada. Assim, fica a sugestão de fazer o mapeamento completo, considerando outras tramitações não só deste, e incluindo no fluxo dos processos a etapa de cobranças administrativas de empresas inadimplentes, como os demais processos realizados pela Central de Aquisições.

\section{REFERÊNCIAS}

ADAIR, C. B.; MURRAY, B. A.. Revolução total dos processos. São Paulo: Nobel, 1996.
ALBUQUERQUE, A.; ROCHA, P.. Sincronismo organizacional. São Paulo: Saraiva, 2007. 
ARAÚJO, J.; ÁLVAREZ E. J. V.. La Modernización

Administrativa y La Gobernanza em los Concellos del Eixo Atlântico do Noroeste Peninsular. Vigo: Eixo Atlântico do Noroeste Peninsular, 2009.

ARAÚJO, L. C. G.. Organização, sistemas e métodos: e as tecnologias de gestão organizacional. São Paulo: Atlas, 2012.

BALDAM, R.; VALLE, R.; ROZENFELD, H.. Gerenciamento de processos de negócios: BPM - Business Process Management. 2 ed. São Paulo: Érica, 2007.

BATISTA, F. F.. Passos para o gerenciamento efetivo de processos no setor Público: aplicações práticas. Brasília: IPEA, 1996.

BIAZZO, S.. Approaches to business process analisys: a review. Business Process Management Journal, v.6, n.2, p.99-112, 2000.

BOAVENTURA, E. M.. Metodologia Científica. São Paulo: Atlas, 2004.

BRASIL. Lei $\mathbf{n . 8 6 6 6}$ de 21 de junho de 1993. Regulamenta o art. 37, inciso XXI, da Constituição Federal, institui normas para licitações e contratos da Administração Pública e dá outras providências. Brasília: DOU, 1993.

CAMPOS, J. P.. Mapeamento de Processos: uma estratégia vencedora. Campinas: 2009.

CAMPOS, R.; LIMA, S.. Mapeamento de processos: importância para as organizações. Rio de Janeiro: Universidade Federal Rural do Rio de Janeiro, 2012.

CATELLI, A.; SANTOS, E. S.. Mensurando a Criação de Valor na Gestão Pública. Revista de Administração Pública, São Paulo, v.38, n.3, p.423-499, 2004.

CHANG, J. F.. Business Process Management Systems: Strategy and Implementation. Boca Raton: Auerbach, 2006.

CHIAVENATO, I.. Administração dos Novos Tempos. 2 ed. Rio de Janeiro: Campus, 2010.

CRUZ, T.. BPM \& BPMS: business process management \& business management systems. 2 ed. Rio de Janeiro: Brasport, 2010.

CRUZ, T.. Sistemas, Métodos \& Processos: Administrando organizações por meio de Processos de Negócios. 2 ed. São Paulo: Atlas, 2005.

DAMELIO, R.. The Basics of Process Mapping. 2 ed. Boca Raton: CRC Press, 2011.

DINSMORE, P.; CABANIS-BREWIN, J.. AMA: Manual de Gerenciamento de Projetos. 2 ed. Rio de Janeiro: Brasport, 2014.

FADUL, E. M. C.; SILVA, P.. Retomando o debate sobre a Reforma do Estado e a Nova Administração Pública. In: ENCONTRO DA ANPAD, 32. Anais. Rio de Janeiro: ANPAD, 2008.
FENILI, R.. Boas práticas administrativas em compras e contratações públicas. Rio de Janeiro: Impetus, 2016.

GARETH, M.. As imagens da organização: vantagens e desvantagens. São Paulo: Atlas, 2006.

GIL, A. C.. Métodos e técnicas de pesquisa social. 6 ed. São Paulo: Atlas, 2008.

GONÇALVES, J. E. L.. As empresas são grandes coleções de processos. Revista de Administração de Empresas, Rio de Janeiro, v.40, n.1, p.6-19, 2000.

HARRINGTON, H. J.. Aperfeiçoando os processos empresariais: estratégia revolucionária para o aperfeiçoamento da qualidade, da produtividade e da competitividade. São Paulo: Makron Books, 1993.

HUNT, V. D.. Process mapping: how to reengineer your business processes. New York: John Wiley \& Sons, 1996.

JOHANSSON, H. J.; MCHUGH, P.; PEDLEBURY, A. J.; WHELLER, A. W.. Processos de negócios. São Paulo: Pioneira, 1995.

LEAL, F.. Um diagnóstico do processo de atendimento a clientes em uma agência bancária através de mapeamento do processo e simulação computacional. Dissertação (Mestrado em Engenharia de Produção) - Universidade Federal de Itajubá, Itajubá, 2003.

LEENDERS, M. R.; FEARON, H. E.. Purchasing and Supply Management. 11 ed. Boston: McGraw-Hill, 1997.

LIMA, M. B. B. P. B.. A gestão da qualidade e o redesenho de processos como modelo de desenvolvimento organizacional em hospitais públicos universitários: o caso do Hospital das Clínicas da UNICAMP. Dissertação (Mestrado) - Universidade de Campinas, Campinas, 2007.

MADIOLO, A. S.; MORISHITA, C. S.; LIZARELLI, F. L.; MARTINS, M. F.; ITO, M. A. O.. Gestão dos processos em uma empresa do setor elétrico. GEPROS, Bauru, n.2, p.31-39, 2000.

MARANHÃO, M.; MACIEIRA, M. E.. O processo nosso de cada dia: modelagem de processos de trabalho. Rio de Janeiro: Qualitymark, 2004.

MARTIN, J.. A grande transição: usando as sete disciplinas da engenharia da empresa para reorganizar pessoas, tecnologia e estratégia. São Paulo: Campus, 2001.

MELLO, A. E. N. S.. Aplicação do Mapeamento de Processo e da simulação no desenvolvimento de projetos de processos produtivos. Dissertação (Mestrado) - Universidade Federal de Itajubá, Itajubá, 2011.

MELO, M. H.. A Gestão da Qualidade Total e as perspectivas dessa tendência nos serviços públicos. Dissertação (Mestrado em Contabilidade) - Universidade Federal da Paraíba, João Pessoa, 2000.

MPOG. Ministério do Planejamento, Desenvolvimento e Gestão. Guia de Gestão de Processos de Governo. Brasília: MPOG, 2011. 
OLIVER, P. R. C.. Projetos de ECM/BPM: Os Segredos da Construção. São Paulo: 2010.

QUINN, J. B.. Intelligent enterprises. New York: Free Press, 1992.

RICHARDSON, R. J.. Pesquisa social: métodos e técnicas. 3 ed. São Paulo: Atlas, 2007.

ROTHER, M.; SHOOK, J.. Learning to See. Boston: The Lean Enterprise Institute, 2000.

SILVA, R. C.; BARKI, T. V. P.. Compras públicas compartilhadas: a prática das licitações sustentáveis. Revista do Serviço Público, v.63, n.2, p.157-175, 2012.

SMITH, H.; FINGAR, P.. Business Process Management: The Third Wave. Tallahassee: Meghan-Kiffer, 2007.
TAVARES, M. C.. Gestão Estratégica. 3 ed. São Paulo: Atlas, 2011.

TEIXEIRA, H. J.; PRADO FILHO, L. P.; NASCIMENTO, F.. Concentração de compras e melhoria da qualidade do gasto público no Brasil. In: CONGRESSO CONSAD DE GESTÃO PÚBLICA, 8. Anais. Brasília: 2015.

TORRES, M. D. F.. Fundamentos da Administração Pública Brasileira. Rio de Janeiro: FGV, 2012.

VERGARA, S. C.. Projetos e relatórios de pesquisa em administração. 13 ed. São Paulo: Atlas, 2011.

VILLELA, C. S. S.. Mapeamento de Processos como Ferramenta de Reestruturação e Aprendizado Organizacional. Dissertação (Mestrado) - Universidade Federal de Santa Catarina, Florianópolis, 2000.

YIN, R. K.. Estudo de caso: Planejamento e métodos. 4 ed. Porto Alegre: Bookman, 2010.

A CBPC - Companhia Brasileira de Produção Científica (CNPJ: 11.221.422/0001-03) detém os direitos materiais desta publicação. Os direitos referem-se à publicação do trabalho em qualquer parte do mundo, incluindo os direitos às renovações, expansões e disseminações da contribuição, bem como outros direitos subsidiários. Todos os trabalhos publicados eletronicamente poderão posteriormente ser publicados em coletâneas impressas sob coordenação da Sustenere Publishing, da Companhia Brasileira de Produção Científica e seus parceiros autorizados. Os (as) autores (as) preservam os direitos autorais, mas não têm permissão para a publicação da contribuição em outro meio, impresso ou digital, em português ou em tradução. 